NASA/TM-2010-216244

AIAA-2009-5319

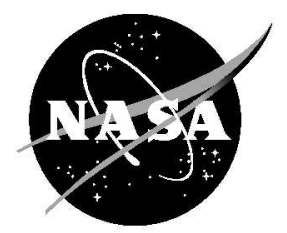

\title{
Pressure Decay Testing Methodology for Quantifying Leak Rates of Full-Scale Docking System Seals
}

Patrick H. Dunlap, Jr.

Glenn Research Center, Cleveland, Ohio

Christopher C. Daniels, Janice L. Wasowski, and Nicholas G. Garafolo

The University of Akron, Akron, Ohio

Nicholas Penney

Ohio Aerospace Institute, Brook Park, Ohio

Bruce M. Steinetz

Glenn Research Center, Cleveland, Ohio 


\section{NASA STI Program . . . in Profile}

Since its founding, NASA has been dedicated to the advancement of aeronautics and space science. The NASA Scientific and Technical Information (STI) program plays a key part in helping NASA maintain this important role.

The NASA STI Program operates under the auspices of the Agency Chief Information Officer. It collects, organizes, provides for archiving, and disseminates NASA's STI. The NASA STI program provides access to the NASA Aeronautics and Space Database and its public interface, the NASA Technical Reports Server, thus providing one of the largest collections of aeronautical and space science STI in the world. Results are published in both non-NASA channels and by NASA in the NASA STI Report Series, which includes the following report types:

- TECHNICAL PUBLICATION. Reports of completed research or a major significant phase of research that present the results of NASA programs and include extensive data or theoretical analysis. Includes compilations of significant scientific and technical data and information deemed to be of continuing reference value. NASA counterpart of peer-reviewed formal professional papers but has less stringent limitations on manuscript length and extent of graphic presentations.

- TECHNICAL MEMORANDUM. Scientific and technical findings that are preliminary or of specialized interest, e.g., quick release reports, working papers, and bibliographies that contain minimal annotation. Does not contain extensive analysis.

- CONTRACTOR REPORT. Scientific and technical findings by NASA-sponsored contractors and grantees.
- CONFERENCE PUBLICATION. Collected papers from scientific and technical conferences, symposia, seminars, or other meetings sponsored or cosponsored by NASA.

- SPECIAL PUBLICATION. Scientific, technical, or historical information from NASA programs, projects, and missions, often concerned with subjects having substantial public interest.

- TECHNICAL TRANSLATION. Englishlanguage translations of foreign scientific and technical material pertinent to NASA's mission.

Specialized services also include creating custom thesauri, building customized databases, organizing and publishing research results.

For more information about the NASA STI program, see the following:

- Access the NASA STI program home page at http://www.sti.nasa.gov

- E-mail your question via the Internet to help@ sti.nasa.gov

- Fax your question to the NASA STI Help Desk at $443-757-5803$

- Telephone the NASA STI Help Desk at 443-757-5802

- Write to: NASA Center for AeroSpace Information (CASI) 7115 Standard Drive Hanover, MD 21076-1320 
NASA/TM-2010-216244

AIAA-2009-5319

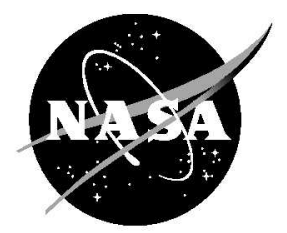

\section{Pressure Decay Testing Methodology for Quantifying Leak Rates of Full-Scale Docking System Seals}

Patrick H. Dunlap, Jr.

Glenn Research Center, Cleveland, Ohio

Christopher C. Daniels, Janice L. Wasowski, and Nicholas G. Garafolo

The University of Akron, Akron, Ohio

Nicholas Penney

Ohio Aerospace Institute, Brook Park, Ohio

Bruce M. Steinetz

Glenn Research Center, Cleveland, Ohio

Prepared for the

45th Joint Propulsion Conference and Exhibit

cosponsored by AIAA, ASME, SAE, and ASEE

Denver, Colorado, August 2-5, 2009

National Aeronautics and

Space Administration

Glenn Research Center

Cleveland, Ohio 44135 


\section{Acknowledgments}

The authors would like to thank the Low Impact Docking System (LIDS) team from NASA Johnson Space Center (JSC) for their support on this project. The authors would also like to acknowledge Erhard Hartman, Gilcrest Electrical \& Supply

Company, for his contributions in performing the seal leak tests and Parker Hannifin Corporation's Composite Sealing Systems Division (San Diego, CA) for fabricating the seal test specimens.

Trade names and trademarks are used in this report for identification only. Their usage does not constitute an official endorsement, either expressed or implied, by the National Aeronautics and Space Administration.

Level of Review: This material has been technically reviewed by technical management.

Available from

NASA Center for Aerospace Information 7115 Standard Drive

Hanover, MD 21076-1320
National Technical Information Service 5301 Shawnee Road Alexandria, VA 22312

Available electronically at http://gltrs.grc.nasa.gov 


\title{
Pressure Decay Testing Methodology for Quantifying Leak Rates of Full-Scale Docking System Seals
}

\author{
Patrick H. Dunlap, Jr. \\ National Aeronautics and Space Administration \\ Glenn Research Center \\ Cleveland, Ohio 44135 \\ Christopher C. Daniels, Janice L. Wasowski, and Nicholas G. Garafolo \\ The University of Akron \\ Akron, Ohio 44325 \\ Nicholas Penney \\ Ohio Aerospace Institute \\ Brook Park, Ohio 44142 \\ Bruce M. Steinetz \\ National Aeronautics and Space Administration \\ Glenn Research Center \\ Cleveland, Ohio 44135
}

\begin{abstract}
NASA is developing a new docking system to support future space exploration missions to low-Earth orbit and the Moon. This system, called the Low Impact Docking System, is a mechanism designed to connect the Orion Crew Exploration Vehicle to the International Space Station, the lunar lander (Altair), and other future Constellation Project vehicles. NASA Glenn Research Center is playing a key role in developing the main interface seal for this docking system. This seal will be relatively large with an outside diameter in the range of 54 to $58 \mathrm{in}$. (137 to $147 \mathrm{~cm})$. As part of this effort, a new test apparatus has been designed, fabricated, and installed to measure leak rates of candidate full-scale seals under simulated thermal, vacuum, and engagement conditions. Using this test apparatus, a pressure decay testing and data processing methodology has been developed to quantify full-scale seal leak rates. Tests performed on untreated $54 \mathrm{in}$. diameter seals at room temperature in a fully compressed state resulted in leak rates lower than the requirement of less than $0.0025 \mathrm{lbm}$, air per day $(0.0011 \mathrm{~kg} /$ day $)$.
\end{abstract}

\section{Nomenclature}

$a_{0} \quad$ linear regression constant

$a_{1} \quad$ linear regression constant that corresponds to seal leak rate

AO atomic oxygen

CBM Common Berthing Mechanism

CEV Crew Exploration Vehicle

CVCM collected volatile condensable materials

$e_{a 1} \quad$ standard error of $a_{1}$

EDU Engineering Development Unit

GRC Glenn Research Center

ISS International Space Station

JSC Johnson Space Center

LEO low-Earth orbit

LIDS Low Impact Docking System 


$\begin{array}{ll}m & \text { mass } \\ \dot{m} & \text { seal leak rate } \\ m_{\max } & \text { maximum mass value for a data set } \\ m_{\min } & \text { minimum mass value for a data set } \\ n & \text { number of samples (i.e., time steps) included in leak rate calculation } \\ p & \text { pressure } \\ R & \text { gas constant for a specific gas } \\ t & \text { time } \\ t_{v, 95 \%} & \text { Student's t-distribution for } 95 \% \text { confidence interval } \\ \bar{t} & \text { interpolated time for which gage pressure is one atmosphere } \\ T & \text { absolute temperature } \\ \mathrm{TML} & \text { total mass loss } \\ u_{x} & \text { uncertainty of variable } x \\ \mathrm{UV} & \text { ultraviolet radiation } \\ V & \text { volume of air in test section }\end{array}$

\section{Introduction}

\section{A. Low Impact Docking System}

NASA is developing the Low Impact Docking System (Ref. 1) (LIDS) (Fig. 1) to enable in-space mating of the various vehicles, modules, and structures that will be used for future missions to the International Space Station (ISS) and the Moon in support of the Vision for Space Exploration (Ref. 2). To implement this vision, NASA's Constellation Program is developing an architecture of new vehicles that includes the human-rated Orion Crew Exploration Vehicle (CEV) and Altair Lunar Lander as well as a collection of launch and transfer vehicles and future destination surface systems.

LIDS will have unique performance attributes compared to previous docking systems and is intended to provide fundamental benefits to NASA as the next generation of space vehicles is developed. The LIDS mating system will be an improvement over existing docking systems in that it eliminates the need for high-velocity docking, provides a standard interface that is easily reconfigurable, and supports a wide range of crewed and autonomous vehicle mating and assembly operations. The overall LIDS project is being led by NASA Johnson Space Center (JSC) with other NASA centers leading specific areas of development for this new docking system.
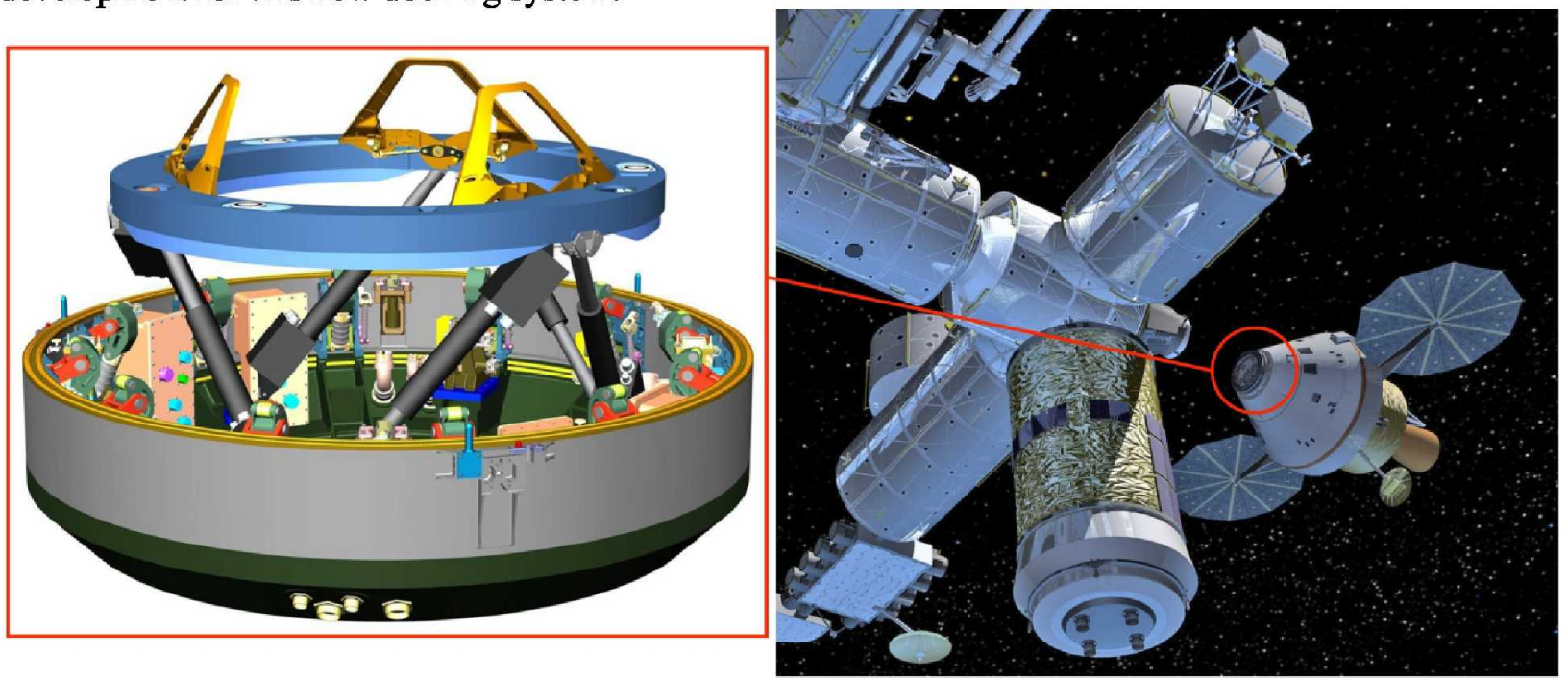

Figure 1.-LIDS model (left) and location on Orion Crew Exploration Vehicle (right) as it prepares to dock to the ISS. 


\section{B. Main Interface Seal}

NASA Glenn Research Center (GRC) is developing the main interface seal for the top of the LIDS tunnel (Fig. 2). This seal will be relatively large with an outside diameter in the range of 54 to $58 \mathrm{in}$. (137 to $147 \mathrm{~cm}$ ). During docking, the latches of the LIDS hard capture system compress the sealing surface on the mating vehicle against the elastomer bulbs on the seal to form a low-leakage interface that helps contain breathable air inside the mated vehicles during a mission.

The baseline design for the LIDS main interface seal is a Gask-O-Seal composite seal assembly produced by Parker Hannifin Corporation (San Diego, CA) (Fig. 3) (Ref. 3). The Gask-O-Seals that are being evaluated are formed by molding silicone elastomer seals directly into the grooves of an aluminum retainer. This design has a space flight pedigree and was used as a static seal in multiple locations on the ISS including seals for the Common Berthing Mechanism (Ref. 4) (CBM), windows, hatches, and electrical connectors.

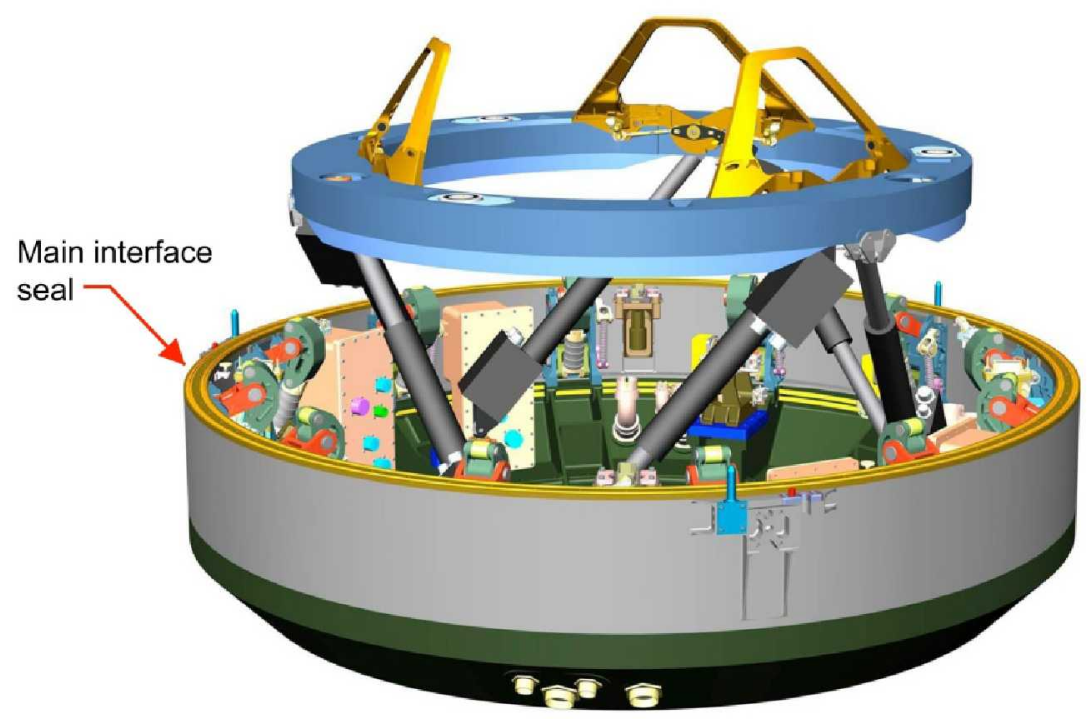

Figure 2.-Location of main interface seal on an active LIDS.

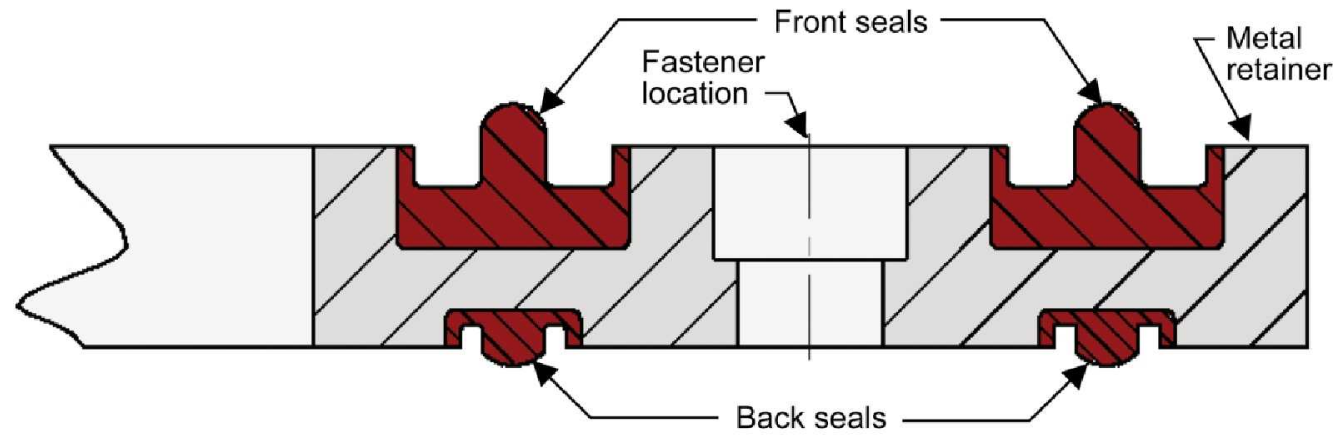

Figure 3.-Cross section through Gask-O-Seal showing silicone seals molded into grooves on front and back surfaces of aluminum retainer. 


\section{Main Interface Seal Requirements}

The LIDS main interface seal must be able to form an effective, low-leakage seal under challenging conditions that include exposure to space environments and off-nominal docking conditions. Seal requirements that are applicable to the current study are summarized in this section. A more thorough review of the requirements for the LIDS main interface seal can be found in the paper by Dunlap et al. (Ref. 5).

\section{Leak Rate}

The most important function for the LIDS main interface seal is to minimize leakage through the interface between two mated systems. Leak rates less than $0.0025 \mathrm{lbm}$ of air $(\mathrm{lbm}$, air) per day $(0.0011 \mathrm{~kg} / \mathrm{day})$ are required at this interface to ensure that the astronauts have sufficient breathable air for extended missions to the ISS or the Moon. With the many requirements being imposed upon the main interface seal, achieving this leak rate requirement is a challenge.

\section{Environments}

When LIDS is in an unmated state during a mission, the main interface seal will be exposed to the space environment for potentially long periods of time. Depending on the type of mission, that environment could be low-Earth orbit (LEO), lunar orbit, the lunar surface, or transit to or from the Moon. Each of these environments presents conditions that may be detrimental to the performance of the main interface seal. During all of these missions, the seal will be exposed to ultraviolet (UV) and ionizing radiation as well as potential impacts from micrometeoroids. In LEO, the seals will also be exposed to atomic oxygen (AO) and impacts from orbital debris. Missions to the Moon pose another challenge wherein the seals will have to contend with the possible deposition of lunar dust on critical sealing surfaces.

After being exposed to all of these challenging environments, the seal will have to allow two spacecraft to mate and then exhibit very little leakage from the pressurized habitat inside of LIDS to the hard vacuum of space surrounding the vehicles. The nominal internal pressure that the seals will have to seal against is $14.7 \mathrm{psia}(101 \mathrm{kPa})$, and the maximum internal pressure is $15.55 \mathrm{psia}(107 \mathrm{kPa})$ based on the maximum design pressure for the CEV (Ref. 6).

While the temperatures of structures in space can vary greatly depending on their orientation and proximity to the Sun, the LIDS main interface seal operating temperature range is currently defined as -58 to $167^{\circ} \mathrm{F}\left(-50\right.$ to $75^{\circ} \mathrm{C}$ ) (Ref. 7). This is the range of temperatures over which the seal must allow LIDS docking and undocking to occur. In addition, the main interface seal must meet the aforementioned leak rate goal over a steady-state pressurized temperature range from 39 to $113^{\circ} \mathrm{F}\left(4\right.$ to $\left.45^{\circ} \mathrm{C}\right)(\operatorname{Ref} .7)$. The low end of this temperature range was set so that the LIDS meets un-crewed dew point temperature limits. The upper end of the range was based on maximum touch temperature limits (Ref. 8).

\section{Mating Configuration}

The baseline mating configuration for LIDS includes an "active" LIDS with a seal on its docking interface and a "passive" LIDS with a flat, smooth metal plate for its sealing surface. When active and passive LIDS systems dock with each other, this arrangement results in "seal-on-plate" mating at the sealing interface (Fig. 4). 


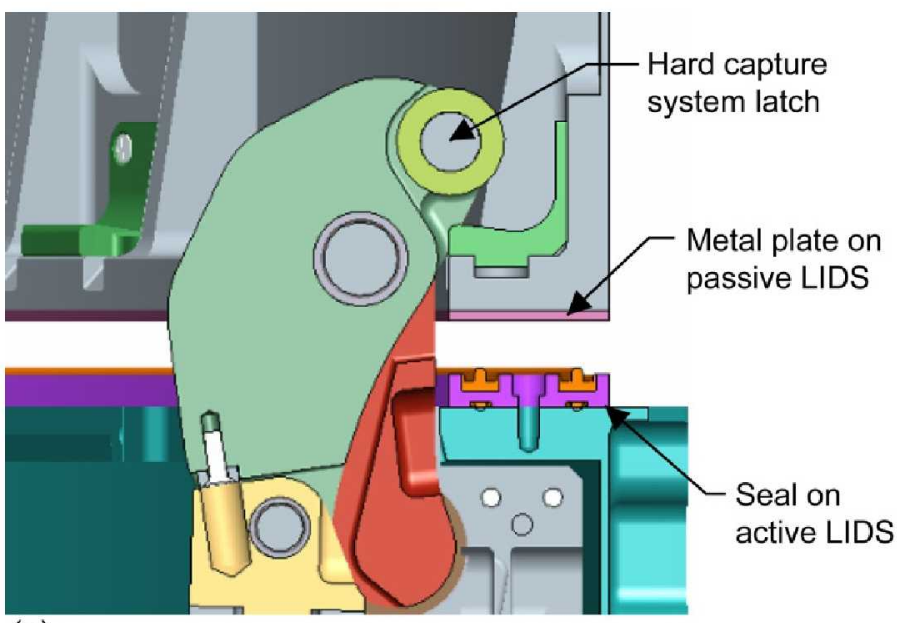

(a)

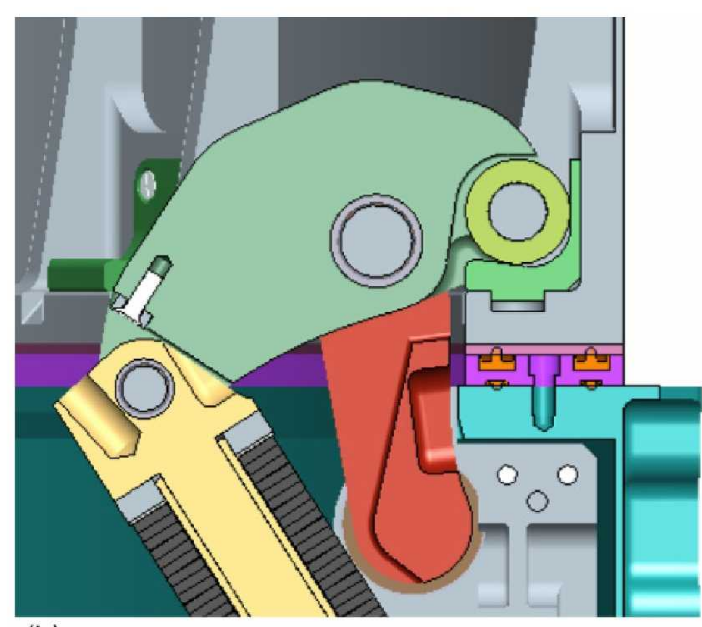

(b)

Figure 4.-Seal-on-plate mating at active LIDS-to-passive LIDS interface (a) just before hard capture system latches engage and (b) after latches have fully compressed the seal.

\section{Use of Low Outgassing Materials}

When subjected to vacuum conditions, some materials tend to outgas and release trace amounts of contaminants. These contaminants can then deposit on other nearby surfaces. This is a problem in space because contaminants that land on critical surfaces such as windows, lenses, star trackers, solar arrays, radiators, and other surfaces with highly controlled optical properties can compromise the functionality of those systems. To mitigate this effect, NASA has implemented technical standard NASA-STD-(I)-6016 Standard Materials and Processes Requirements for Spacecraft (Ref. 9). This document states that nonmetallic materials which are exposed to space vacuum shall have a total mass loss (TML) of less than $1 \%$ and a collected volatile condensable materials (CVCM) of less than $0.1 \%$ when tested using the technique of ASTM-E595 (Ref. 10). Because the LIDS main interface seal includes elastomer seals as the main sealing elements, the elastomer selected for this application must meet the aforementioned outgassing requirements.

\section{Use of Redundant Sealing Features}

Structural design requirements for Constellation flight hardware require that all seal locations with diameters larger than $6.0 \mathrm{in}$. $(15 \mathrm{~cm})$ have a minimum of two seals at that interface (Ref. 11). Because the LIDS main interface seals will likely have an outer diameter ranging from 54 to 58 in. (137 to $147 \mathrm{~cm}$ ), redundant sealing features must be implemented.

\section{Goals for Current Study}

The goals for this study are as follows:

1. Develop a test methodology for measuring the leakage of full-scale LIDS main interface seals

2. Perform leak tests on 54-in. diameter seals at room temperature to demonstrate this methodology

3. Compare leak rates measured for the 54-in. diameter seals to the maximum allowable leak rate for the LIDS main interface seal 


\section{Test Apparatus and Procedures}

\section{A. Seal Test Specimens}

The seals that were evaluated in this study were designed for use in the 54-in. diameter LIDS Engineering Development Unit (EDU-54). As noted earlier, the baseline design is a Gask-O-Seal that is formed by vacuum molding silicone elastomer seal bulbs directly into the grooves of an aluminum retainer. 7075-T651 aluminum was selected as the material for the EDU-54 main interface seal retainer, and the elastomer seal bulbs were made of silicone compound S0383-70, a formulation produced by Parker Hannifin Corporation. When properly processed and cured, this material meets the low outgassing requirements of less than $1 \%$ TML and less than $0.1 \%$ CVCM.

As illustrated in Figure 5, the seal has dual bulbs on both the front and back sides of the retainer to meet the redundancy requirement. The cross sections of the two front seal bulbs were identical. The back seal bulbs were also identical, although their dimensions were different than those for the front seals. Also shown in Figure 5 are the key dimensions of the seal assembly. The outer diameter, 54 in., and face width, 1.125 in., were selected so that the seal would fit on the flange of the EDU-54 tunnel where it is installed. The thickness of the retainer is $0.200 \pm 0.003$ in. Three alignment pin holes in the retainer are used to align the axes of the seal and the EDU-54 tunnel during seal installation, and 72 socket head fasteners (\#8-32) are used to attach the seal to the top of the tunnel. Figure 6 shows a close up view of the seal installed in the test apparatus. The seal test specimens evaluated in this study were tested in an "as-received" state with no additional pre-treatment applied (i.e., no AO pre-treatment for adhesion reduction (Ref. 12)).

\section{B. Test Apparatus}

Figures 7 and 8 show the main elements of the test apparatus that was used to perform leak tests in this study. This test apparatus is capable of evaluating candidate LIDS main interface seals under simulated thermal, pressure, and engagement conditions. This section describes the main features of the test apparatus and the configuration used to perform tests in this study. Additional information about the test apparatus can be found in the paper by Dunlap et al. (Ref. 5).

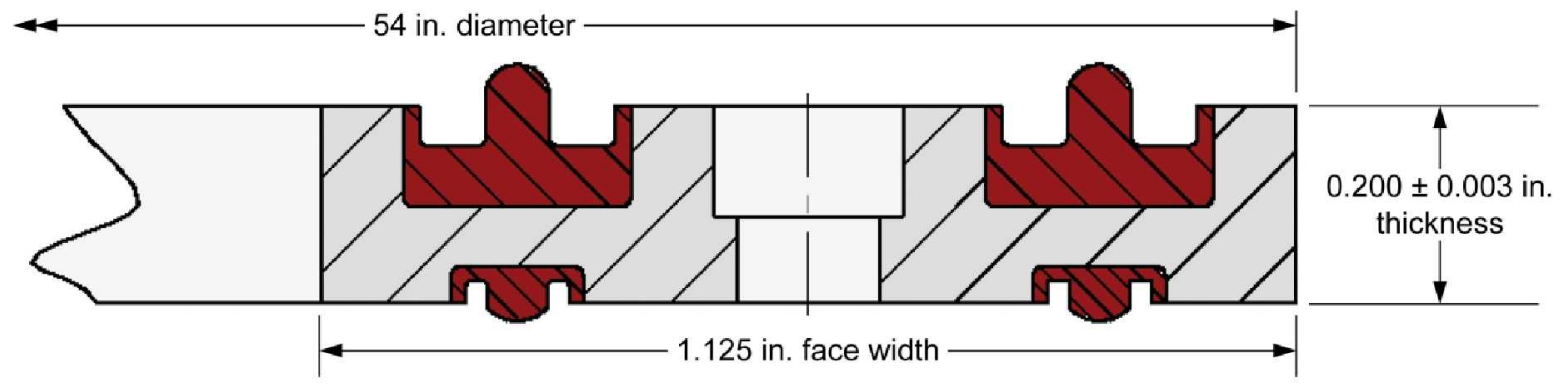

Figure 5.-Key seal dimensions.

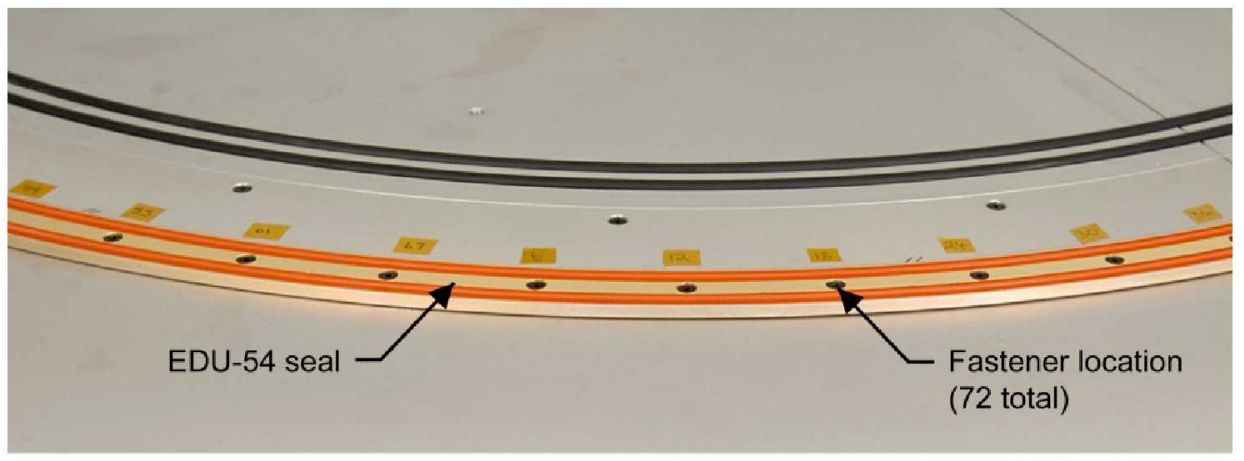

Figure 6.-Photograph of 54-in. diameter EDU-54 seal installed in test apparatus showing dual front seal bulbs and fastener holes. 


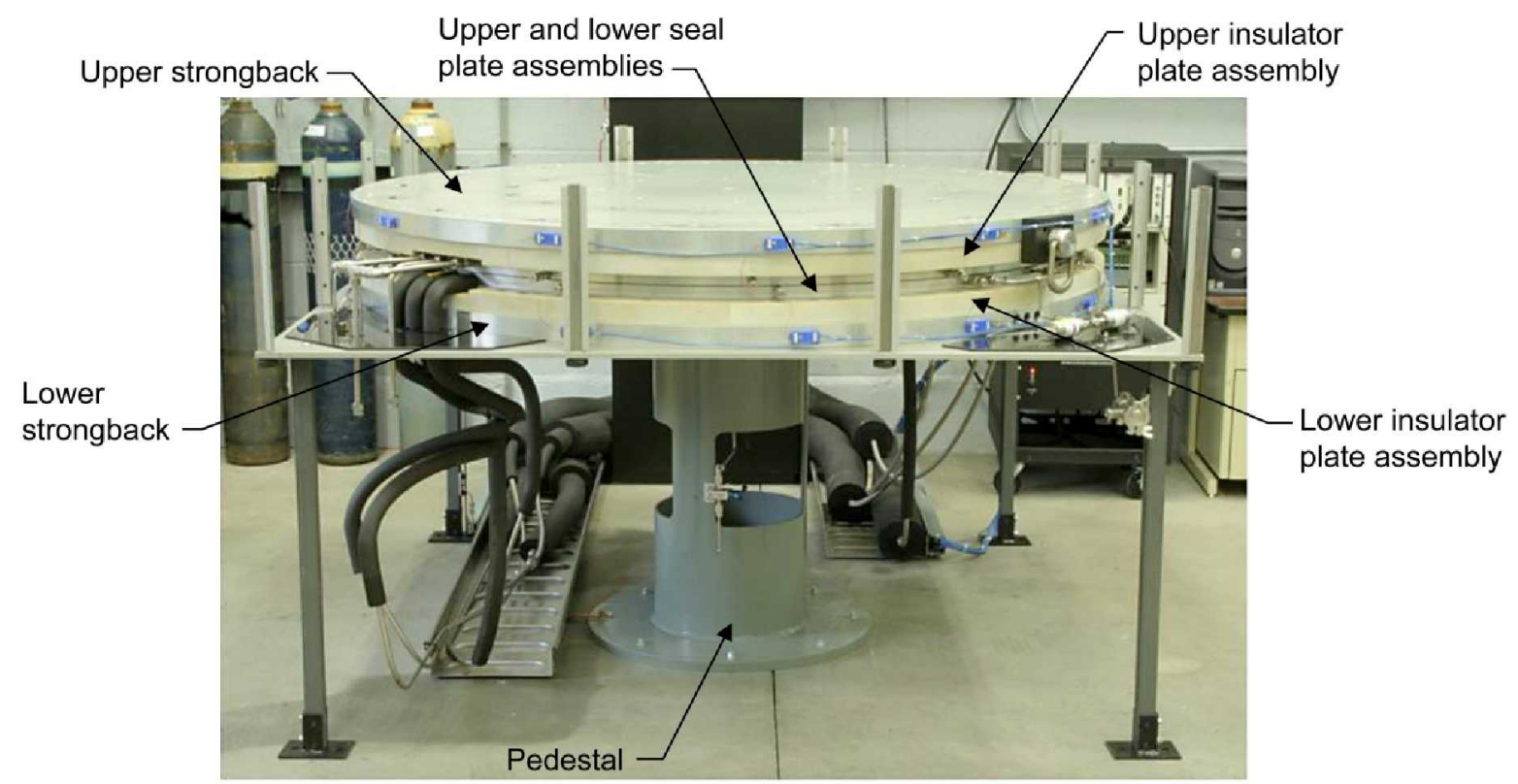

Figure 7.-Main elements of the full-scale non-actuated LIDS seal test apparatus.

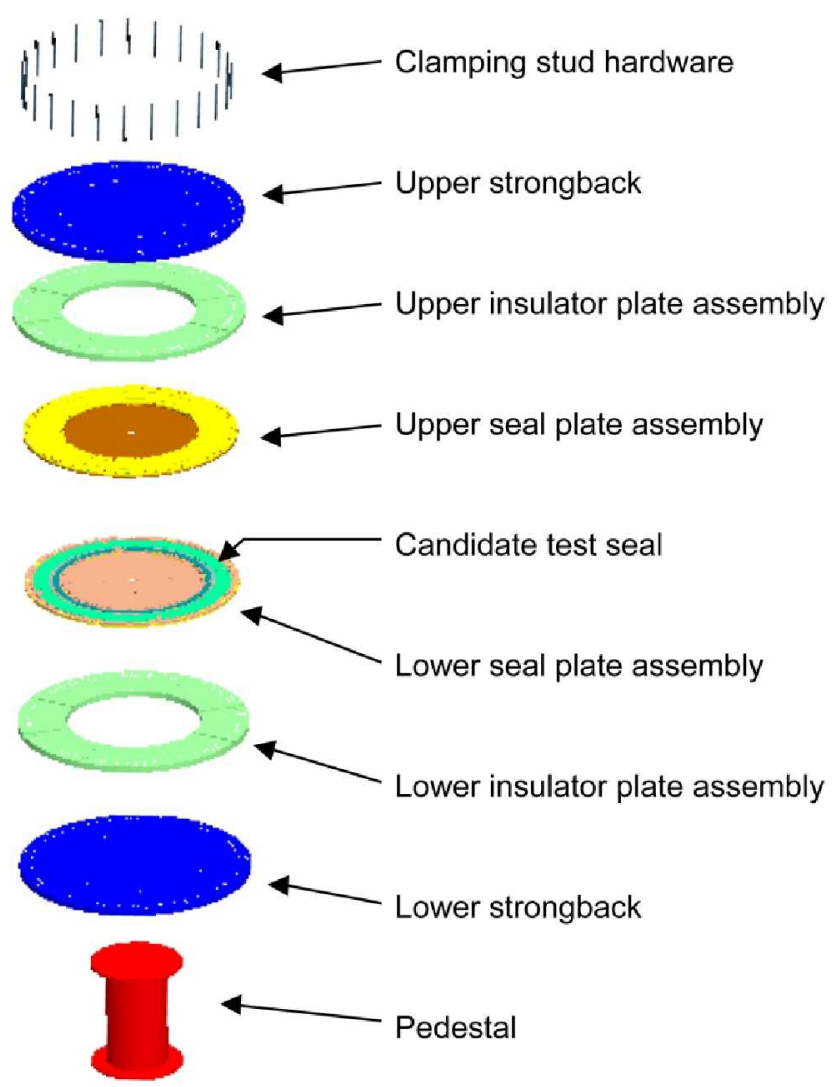

Figure 8.-Exploded view of main elements of the full-scale non-actuated LIDS seal test apparatus. 
At the mid-line of the test apparatus is a pair of seal plate assemblies (upper and lower) that hold the seal test specimens during testing (Fig. 8). Each assembly is composed of a seal cartridge, a pair of heat exchanger plates, and an assortment of O-rings that seal off various volumes in the test apparatus (Fig. 9). To accommodate the variety of candidate seal sizes and designs that are to be evaluated over the course of the LIDS seal development project, the seal cartridge contains a wide, annular pocket with an inner diameter of $47.6 \mathrm{in} .(121 \mathrm{~cm})$ and an outer diameter of $64.5 \mathrm{in.}(164 \mathrm{~cm})$ to accept seals with outer diameters of approximately 52.0 to $60.0 \mathrm{in}$. $(132 \mathrm{to} 152 \mathrm{~cm})$. The depth of the pocket is $0.20 \mathrm{in}$. $(0.51 \mathrm{~cm})$. Different bolt patterns can be machined into this region so that seals of different sizes can be tested. The 54 in. diameter seal test specimens evaluated in this study were installed in this pocket during testing and secured in place by 72 fasteners.

The seal-on-plate test configuration was achieved by installing an aluminum ring with a smooth, flat surface in the upper seal plate assembly (Fig. 10). This ring was made of anodized 7075-T6 aluminum, and its sealing surface was machined to a surface roughness of approximately $16 \mu \mathrm{in}$. The back side of the ring was sealed by a pair of silicone O-rings to minimize leakage through the interface between the ring and the seal cartridge. This sealing interface is present in the test apparatus but not in the actual LIDS seal application. This difference and its influence on the leak rates measured during testing are discussed further in Section III.D of this report.

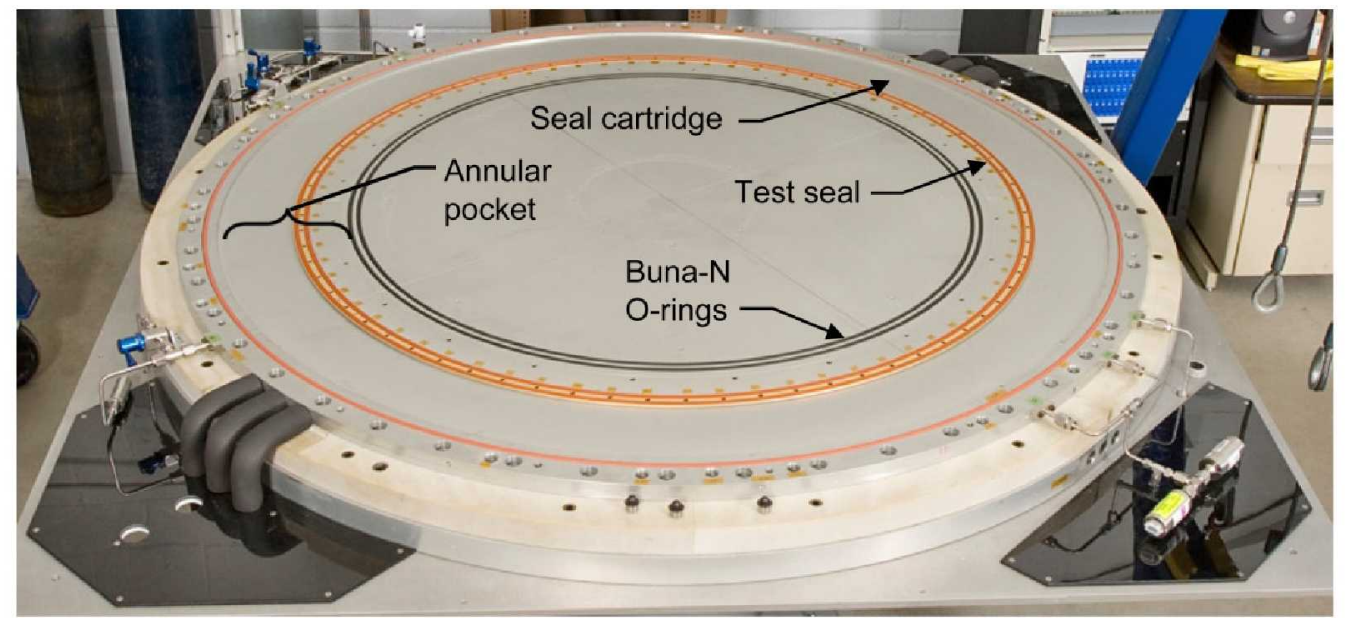

(a)

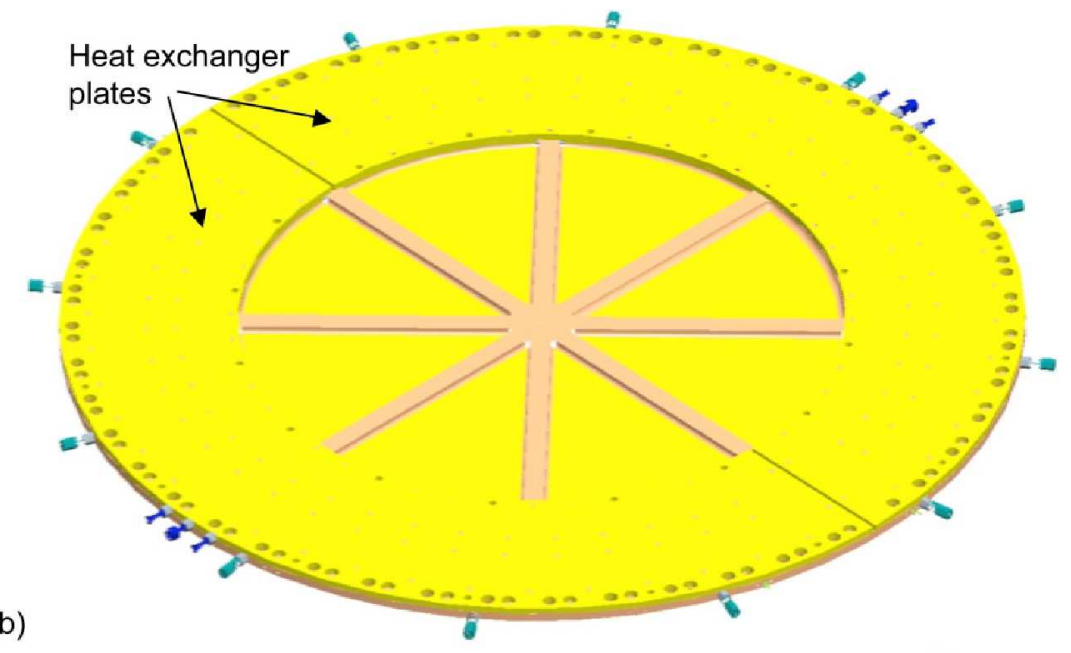

Figure 9.-Photograph of top (a) and schematic of bottom (b) of seal plate assembly showing main components. 


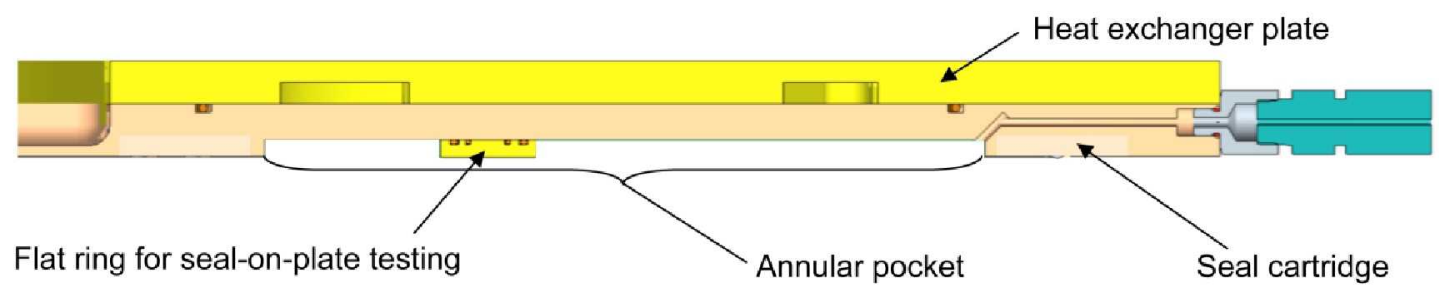

Figure 10.-Cross section of upper seal plate assembly showing flat ring installed for seal-on-plate testing. Note: Back side of flat ring sealed by two silicone O-rings.

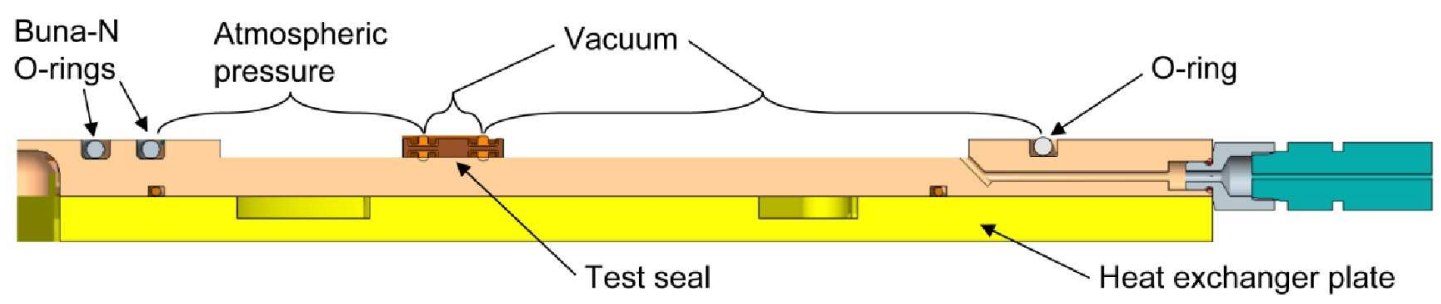

Figure 11.-Cross section through lower seal plate assembly showing test seal and regions of atmospheric pressure and vacuum during leak testing.

The lower seal plate assembly was designed to simulate the required pressure differentials across the seals during testing including LIDS operating conditions in space and pre-flight checkout conditions on the ground. For the tests performed in this study, a pressure differential comparable to what the seals would experience when Orion docks to the ISS was used. Figure 11 shows how on-orbit pressure conditions were generated for these tests. A cross-drilled port (not shown) located in the cavity inboard of the test seal provided air at approximately atmospheric pressure to this region. To prevent the entire cavity inboard of the test seal from being pressurized to atmospheric pressure, a pair of Buna-N O-rings was positioned just inboard of the port to create an annular region of higher pressure inboard of the test seal (Figs. 9(a) and 11). On the outboard side of the seal, a cross-drilled port in that cavity was connected to a vacuum pump to draw the pressure in this region down to gross vacuum conditions. To facilitate this, the cavity outboard of the test seal was sealed near the perimeter of the seal cartridge by an O-ring. The region between the elastomer bulbs of the test seal was also evacuated during testing through a port located in that area. This arrangement generated a pressure differential across the inner bulbs of the test seal of approximately one atmosphere.

The test apparatus is capable of operating over a range of temperatures from -58 to $122^{\circ} \mathrm{F}(-50$ to $50^{\circ} \mathrm{C}$ ), easily covering the required steady-state pressurized temperature range of 39 to $113^{\circ} \mathrm{F}$ ( 4 to $45^{\circ} \mathrm{C}$ ). The desired thermal conditions for a given test are achieved by a pair of heat exchanger plates installed on the back side of each seal plate assembly (Figs. 9(b) to 11). A Two Loop Chiller/Heater, Model 2VLH30W (hereafter referred to as the "temperature control system") produced by Mydax, Incorporated (Auburn, CA) circulates Syltherm HF heat transfer fluid through the plates during testing to heat or cool the test apparatus to the appropriate temperature and maintain that temperature for the duration of the test. Insulator plate assemblies on both the upper and lower halves of the test apparatus (Figs. 7 and 8) insulate the seal plate assemblies during testing. Although tests in this study were only performed at room temperature, the temperature control system was operated during testing to maintain a constant temperature in the test apparatus.

Instrumentation located throughout the test apparatus recorded pressures and temperatures to quantify seal performance during testing. The differential pressure across the test seal was measured during testing with a series of pressure transducers located inboard and outboard of the seal. The pressure on the high pressure side of the test section was monitored by two pressure transducers rated for pressures of 0 to $35 \mathrm{psia}(0$ to $241 \mathrm{kPa}$ ) with a specified accuracy of $\pm 0.75 \%$ of full scale. The pressure on the low pressure 
side of the test section was monitored by two vacuum transducers. The vacuum transducers had a range of 0.0001 to 100 torr $\left(1.33 \times 10^{-5}\right.$ to $\left.13.3 \mathrm{kPa}\right)$ with accuracies of $\pm 5 \%$ in the 0.001 to 100 torr range and $\pm 10 \%$ in the 0.0001 to 0.001 torr range. The pressure between the front seal bulbs was monitored by two transducers, one rated for the high pressure range and one for vacuum conditions. A barometric pressure transducer (accuracy of $\pm 0.00737 \mathrm{psi}$ ) was used to measure the atmospheric pressure in the laboratory during testing.

Seal temperatures were measured by 24 equally spaced type $T$ thermocouples $\left( \pm 0.036^{\circ} \mathrm{C}\right.$ accuracy) divided equally between the two seal cartridges. Those in the lower seal cartridge were installed around the base of the test seal, while those in the upper cartridge were at the base of the flat ring. Two additional type $\mathrm{T}$ thermocouples were used to measure the air temperature inside the test apparatus enclosure and in the laboratory.

\section{Test Procedure}

Leakage tests were performed according to the following procedure. Before each build of the test apparatus, the test seal and the sealing surface on the flat ring were visually inspected and wiped clean using isopropyl alcohol. Once the isopropyl alcohol had evaporated, the test seal was installed in the lower seal cartridge and secured in its proper position using 72 fasteners (Figs. 6 and 9(a)). With the seal installed, the upper half of the test apparatus was lowered into position and secured to the lower half using 24 clamping studs (Fig. 8). All appropriate heat transfer fluid connections were then made to the test apparatus, and the temperature control system was turned on and set up to achieve the desired test temperature. Before a test was started, all test sections inboard (high pressure test section) and outboard (low pressure test section) of the test seal were evacuated with a vacuum pump except for the central region inboard of the pair of Buna-N O-rings. Once the test sections achieved the required vacuum level, they were isolated from each other by way of isolation valves. A vacuum was maintained on the low pressure test section and the section between the seal bulbs from this point onward for the duration of the test. The high pressure test section was supplied with dry air at a pressure slightly above ambient until the test apparatus reached isothermal conditions. At this point the high pressure test section was isolated from the dry air source. Once this was complete, the test was allowed to begin. Test data was collected by way of a LabVIEW (National Instruments)-based data acquisition system with a PC interface. Data was sampled at $50 \mathrm{~Hz}$ and recorded every $10 \mathrm{~s}$ with each recorded value being an average of 25 sampled data points. The data was sampled and stored directly on a hard drive for later processing.

\section{Leak Rate Measurements and Data Processing Methodology}

To quantify leak rates for the candidate seals tested in the full-scale non-actuated LIDS seal test apparatus, a pressure decay methodology was developed and implemented. During testing, pressures and temperatures in the test apparatus and in the laboratory were recorded over time. After the test was completed, the data was processed to calculate the leak rate for the test seal at a differential pressure across the seal of approximately $14.4 \mathrm{psid}$. This calculation was done as follows. A linear regression was performed on a subset of the data using the Least Squares Method, and the time at which the regression crossed $14.4 \mathrm{psig}, \bar{t}$, was linearly interpolated. A new subset of absolute pressure and temperature data was then selected for a range of at least $2 \mathrm{hr}$ before and $2 \mathrm{hr}$ after $\bar{t}$. The absolute pressures of two transducers were then averaged to determine $p_{\text {absolute,average }}$ for each time step. The mass of air in the test section at each time step was then calculated using the Ideal Gas Law according to the following equation:

$$
m=\frac{p_{\text {absolute, average }} \cdot V}{\mathrm{RT}}
$$


A linear regression was then performed on the calculated mass values for the subset of data using the Least Squares Method to yield:

$$
m=a_{1} t+a_{0}
$$

In Equation (2) the variable $a_{1}$ was the slope of the linear regression curve. This value corresponded to the change in mass in the system with respect to time and was equivalent to the leak rate for the inner bulbs of the test seal.

\section{E. Uncertainty and Error Calculations}

An uncertainty analysis of Equation (1) was used to calculate the uncertainty of the mass of the air in the test section, $u_{m}$, at each time step according to the following equation:

$$
u_{m}=m \cdot\left[\left(\frac{u_{V}}{V}\right)^{2}+\left(\frac{u_{p}}{p}\right)^{2}+\left.\left(\frac{u_{T}}{T}\right)^{2}\right|_{\rfloor} ^{1 / 2}\right.
$$

Based on this equation, the uncertainty of the mass at each time step incorporated values for other sources of error including those for measurements from the pressure transducers and thermocouples at each time step as well as the uncertainty of the volume measurement. The uncertainty of the gas constant, $u_{R}$, was not included in Equation (3) since it was assumed that $R$ was a constant.

The standard error for the leak rate, $e_{a 1}$, was calculated and was used to determine the $95 \%$ confidence interval for the seal leak rate, $a_{1}$, as follows:

$$
\left(a_{1}-\mathbf{t}_{v, 95 \%} \frac{e_{a 1}}{\sqrt{n}}, a_{1}+\mathbf{t}_{v, 95 \%} \frac{e_{a 1}}{\sqrt{n}}\right)
$$

Because the data sets used for these calculations were large and had at least 1000 data points, the Student's $t$-distribution for a $95 \%$ confidence interval, $t_{v, 95 \%}$, was 1.96 . The values calculated for the standard error and $95 \%$ confidence interval for the leak rate represent numerical errors for how accurately the best fit line of the regression correlates to the data set.

\section{Test Results and Discussion}

\section{A. Leak Rate Calculations: Regression Method}

To develop and demonstrate the aforementioned testing and data processing methodology, leak tests were performed on full-scale EDU-54 seals at room temperature. Additional leak tests on these seals performed at elevated and reduced temperatures and under partially compressed conditions are reported by Wasowski et al. (Ref. 13).

Figure 12 shows the plot of mass versus time for the leak test performed at room temperature on the inner seal bulbs of the full-scale EDU-54 seal with serial number 001. The seal was fully compressed and tested in an as-received condition with no additional pre-treatment. This figure shows that the mass of the air in the test section decreased as the test progressed indicating that air was indeed leaking through the test seal. Each of the 1440 data points on the plot represents the mass of air in the test section at a particular time over a 4-hr (0.17-day) time period. Using Equation (3) the uncertainty of the mass value for each time step was calculated, and the maximum uncertainty for the data set was determined to be $\pm 8.3 \times 10^{-5} \mathrm{lbm}$, or $\pm 2.4 \%$ of the mass value for that particular time step. 


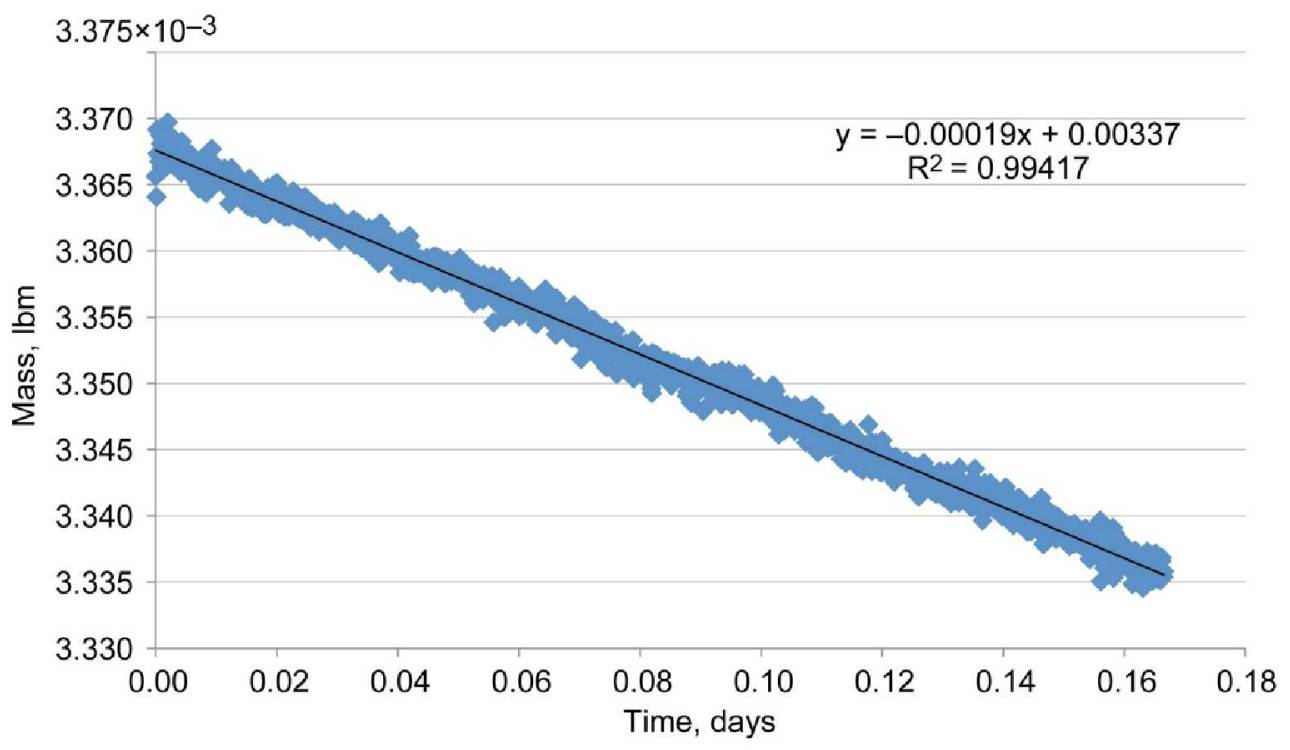

Figure 12.- Plot of mass versus time for leak test performed on inner seal bulbs of fully compressed, full-scale EDU-54 seal, serial number 001. Test performed at room temperature on untreated seal.

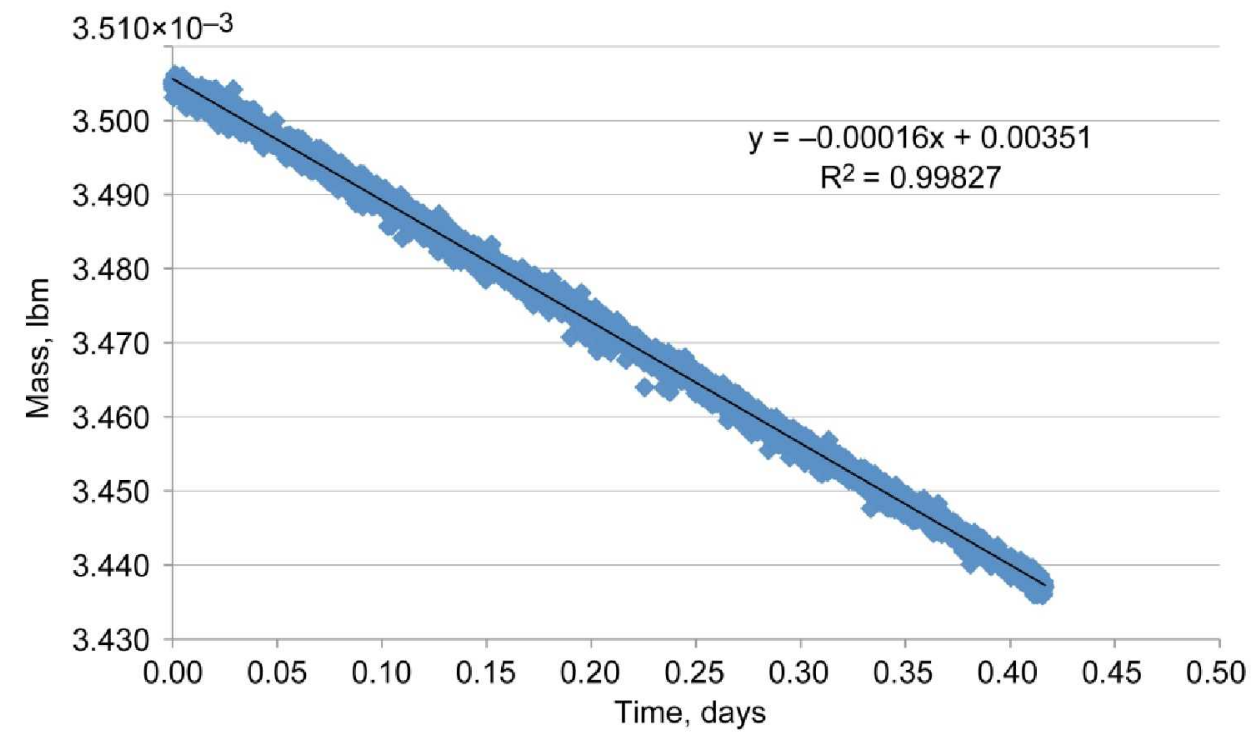

Figure 13.-Plot of mass versus time for leak test performed on inner seal bulbs of fully compressed, full-scale EDU-54 seal, serial number 006. Test performed at room temperature on untreated seal.

Also shown in the plot are the best fit line and the equation for the linear regression. As noted previously in the discussion regarding Equation (2), the slope of this line corresponds to the leak rate for the inner bulbs of the test seal. For this particular seal, the leak rate across the inner bulbs at a differential pressure of $14.4 \mathrm{psid}$ was $1.9 \times 10^{-4} \mathrm{lbm}$, air/day. Additional calculations performed on this data set revealed that the standard error (i.e., numerical error) for this leak rate was $3.9 \times 10^{-7} \mathrm{lbm}$, air/day, or $0.2 \%$ of the leak rate. The $95 \%$ confidence interval for the leak rate was $\pm 2.0 \times 10^{-8} \mathrm{lbm}$, air/day.

Figure 13 shows the plot of mass versus time for the test performed on the full-scale EDU-54 seal with serial number 006 under the same test conditions. The data set for this test included 3600 data points over a 10-hr (0.42-day) time period, and the figure shows a similarly shaped response as that for serial 
number 001 (Fig. 12). An analysis of the data set showed that the maximum uncertainty for the mass values was $\pm 8.2 \times 10^{-5} \mathrm{lbm}$, or $\pm 2.4 \%$ of the mass value for that particular time step.

The leak rate measured for the inner bulbs of this seal was $1.6 \times 10^{-4} \mathrm{lbm}$, air/day which was slightly lower than that measured for the other seal. The standard error for this leak rate was $1.1 \times 10^{-7} \mathrm{lbm}$, air/day $\left(0.07 \%\right.$ of the leak rate), and the $95 \%$ confidence interval was $\pm 3.7 \times 10^{-9} \mathrm{lbm}$, air/day. Note that the standard error and $95 \%$ confidence interval for this test were lower than those for the previous test. This improvement in accuracy was a result of the longer test time $(10 \mathrm{hr})$ utilized for this test as compared to the duration $(4 \mathrm{hr})$ for the test performed on the seal with serial number 001.

\section{B. Maximum Leak Rate Calculations}

As noted earlier, an uncertainty analysis was performed to determine the uncertainty of the mass value for each data point in Figures 12 and 13. The maximum error for these data points was shown to be $2.4 \%$. However, as of the writing of this paper, a method had not yet been developed to calculate the uncertainty of the leak rate value for each test based on the entire set of data points. The values calculated for the standard error and $95 \%$ confidence interval for the leak rate represent numerical errors for how accurately the best fit line of the regression correlates to the data set. However, a thorough treatment of the experimental error has not yet been developed. In lieu of this and in an effort to bound the experimental error and calculate the maximum leak rate for each test, the following approach was taken.

Based in part on data processing methods described by Jackson et al. (Ref. 14) and Smith et al. (Ref. 15) to calculate leak rates for pressure decay tests, the data from two time steps was utilized to calculate the maximum leak rate for both tests. These time steps corresponded to the maximum and minimum mass values within the first and last five minutes of each data set, respectively. Once these data points were identified, the maximum leak rate for each test was calculated using the maximum and minimum mass values and the time steps within the data set at which each occurred:

$$
\dot{m}_{\mathrm{max}}=\frac{m_{\max }-m_{\min }}{t_{m_{\max }}-t_{m_{\min }}}
$$

Using Equation (5), the maximum leak rate calculated for the test performed on the inner bulbs of the seal with serial number 001 was $2.2 \times 10^{-4} \mathrm{lbm}$, air/day. This was $16 \%$ higher than what was calculated using the regression method discussed earlier. Similarly, the maximum leak rate for the inner bulbs of the seal with serial number 006 was determined to be $1.7 \times 10^{-4} \mathrm{lbm}$, air/day, or $6 \%$ higher than the value calculated using the regression method. Because these leak rates were based on the maximum and minimum mass values at the beginning and end of each test, they did not take into account the thousands of other data points recorded for each data set that would tend to attenuate the errors of individual data points. Therefore, it is believed that the leak rates calculated by this alternate method were conservative and should be considered as bounding values for the maximum leak rates for both tests.

\section{Comparison to Maximum Leak Rate Requirement}

As noted earlier, the maximum allowable leak rate for the LIDS main interface seal at a pressure of $14.7 \mathrm{psia}$ is $2.5 \times 10^{-3} \mathrm{lbm}$, air/day. The average leak rate at atmospheric pressure for the two seals that were tested in this study was $1.8 \times 10^{-4} \mathrm{lbm}$, air/day based on the regression method of data processing. This was more than an order of magnitude lower than the maximum allowable leak rate. Using the alternate method described in the previous section, the average maximum leak rate was $2.0 \times 10^{-4} \mathrm{lbm}$, air/day. This value was also more than an order of magnitude below the maximum leak rate. Thus, regardless of the data processing method utilized, the seals tested in this study exhibited leak rates that were lower than the maximum allowable leak rate by an order of magnitude. 
The leak rates measured for these 54-in. diameter seals were for the inner bulbs of the seal which have a circumferential length of $164 \mathrm{in}$. Therefore, the average leak rate for the inner bulbs on a per inch basis was $1.1 \times 10^{-6} \mathrm{lbm}$, air/day/in. based on the leak rate calculated using the regression method and $1.2 \times 10^{-6} \mathrm{lbm}$, air/day/in. for the alternate method. The next generation of candidate LIDS main interface seals currently in development has a slightly larger outer diameter of $58 \mathrm{in}$. If the full-scale EDU-54 seal was scaled up to a 58-in. diameter seal with the same seal cross section design, it is estimated that the leak rate for the inner bulbs of such a seal would be $2.1 \times 10^{-4} \mathrm{lbm}$, air/day based on the higher average leak rate from the alternate data processing method. This estimated leak rate would also be more than an order of magnitude lower than the maximum allowable leak rate.

\section{Leakage Paths: LIDS Application Versus Full-Scale Non-Actuated LIDS Seal Test Apparatus}

There are several paths through which air can leak past the main interface seal when LIDS is docked (Fig. 14). Leakage can occur at the interface between the front seal bulbs and the sealing surface on the passive LIDS. Air can also leak through the interface between the back bulbs and the top of the active LIDS tunnel. In addition to leaking between the seals and their sealing interfaces, air can leak through microcracks in the seals and permeate through the semi-porous silicone seal material.

All of these leak paths are also present when candidate seals are leak tested in the full-scale nonactuated LIDS seal test apparatus. However, the design of the test apparatus also allows for leakage past the sealing interface in other locations. As shown in Figure 10, seal-on-plate leak tests are performed in the test apparatus by installing a flat ring in the upper seal plate assembly. This feature was included in the test apparatus so that either a flat ring or seal could be installed in the upper seal cartridge to allow leak tests to be performed in either a seal-on-plate or seal-on-seal configuration, respectively. This modular design also allows different flat ring designs to be installed to test against sealing surfaces with various surface roughnesses, flatnesses, or other surface features. However, the use of a removable flat ring introduced additional leak paths around the back side of the ring that are not present in the actual LIDS application. During testing, the back side of the flat ring is typically sealed by a pair of elastomer O-rings. This configuration introduces additional leakage paths both around and through the O-rings

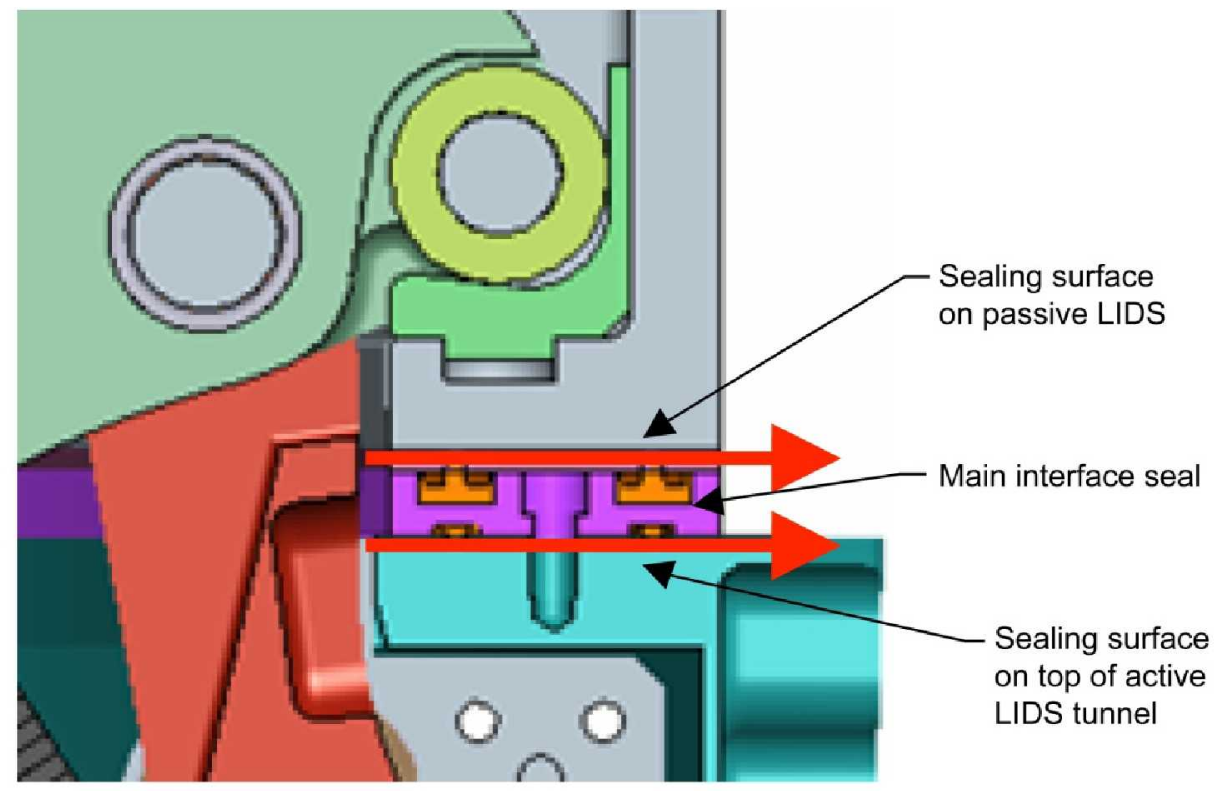

Figure 14.-Leakage paths (red arrows) past main interface seal when LIDS is docked. 
during a leak test. Because these leak paths are present in the test apparatus but not in the actual LIDS main interface seal application, it is believed that the leak rates that were measured for the candidate seal designs were conservative, and actual leak rates for the seals when installed on the LIDS tunnel will be lower.

Steps are being taken to minimize the leakage through these additional leak paths for future leak tests. Instead of using elastomer-based O-rings to seal the back side of the flat rings, researchers are considering using metal wire seals that would produce near-hermetic sealing at this interface. Another option is to eliminate the modular flat ring design altogether and have the test seals seal directly against the surface of the upper seal cartridge. Both of these options are being considered for future tests.

\section{Summary and Conclusions}

NASA is developing the LIDS docking system to support future space exploration missions to LEO and the Moon. While NASA JSC is responsible for overall development of the LIDS, the main interface seal for the top of the LIDS tunnel is being developed by NASA GRC. The primary function of this seal is to minimize the leakage of air through the LIDS-to-LIDS interface when two vehicles mate to ensure that the astronauts have sufficient breathable air for potentially long missions. The maximum allowable leak rate at this interface is $0.0025 \mathrm{lbm}$, air/day.

GRC has developed a unique test apparatus to measure the leak rates of candidate full-scale main interface seals under representative thermal, vacuum, and engagement conditions. Using this test apparatus, test procedures and data processing methodologies have been developed to quantify full-scale seal leak rates based on the pressure decay method. During testing, the pressure and temperature of a known internal volume are monitored and used to calculate the mass of air in the test section at discrete time steps. A minimum of $4 \mathrm{hr}$ of data are then plotted versus time, and a linear regression is performed on the data set to calculate the seal leak rate and associated numerical errors. As of the writing of this paper, though, a method had not yet been developed to calculate the experimental error of the leak rate value for each test when the regression method is applied to an entire set of data points. Therefore, an alternate data processing method was also examined in an effort to bound the maximum leak rate. This method utilized the maximum and minimum mass values within the first and last 5 min of each data set, respectively. In this study, leak tests were performed on the inner seal bulbs of two untreated, fully compressed, full-scale EDU-54 seals at room temperature to develop and demonstrate this methodology. Based on the results of these tests, the following conclusions were made:

1. When using the regression method to calculate inner seal leak rates, the average leak rate was $1.8 \times 10^{-4} \mathrm{lbm}$, air/day. This was more than an order of magnitude lower than the maximum allowable leak rate. Standard numerical errors for the measured leak rates were no greater than $0.2 \%$ of the leak rate, and the $95 \%$ confidence interval was $\pm 2.0 \times 10^{-8} \mathrm{lbm}$, air/day or less.

2. When the alternate data processing method was utilized, the average maximum leak rate that was calculated was $2.0 \times 10^{-4} \mathrm{lbm}$, air/day which was still more than an order of magnitude below the maximum leak rate. It is believed that leak rates calculated using this method were conservative and should be considered as bounding values for the maximum leak rates for this seal design.

3. Overall, leak rates measured for the inner seal bulbs of untreated, fully compressed EDU-54 seals at room temperature were more than an order of magnitude lower than the leak rate requirement regardless of which data processing method was utilized. 


\section{References}

1. Lewis, J.L., Carroll, M.B., Morales, R.H., and Le, T.D., National Aeronautics and Space Administration (U.S. Government), Washington, D.C., "Androgynous, Reconfigurable Closed Loop Feedback Controlled Low Impact Docking System with Load Sensing Electromagnetic Capture Ring," U.S. Patent No. 6,354,540, March 12, 2002.

2. "Constellation Architecture Requirements Document (CARD)," Constellation Program document CxP 70000, Rev C, Change 001, Release Date March 5, 2009.

3. Moyers, W.F., Parker Hannifin Corporation, Cleveland, OH, "Composite Sealing Ring with Compression Stop," U.S. Patent No. 3,195,906, July 20, 1965.

4. "C-1 Common Berthing Mechanism System Brief," JSC-36333 Vol. 2, 15 April 2005.

5. Dunlap, P.H., Daniels, C.C., Steinetz, B.M., Erker, A.H., Robbie, M.G., Wasowski, J.L., Drlik, G.J., Tong, M.T., and Penney, N., "Full-Scale System for Quantifying Leakage of Docking System Seals for Space Applications," NASA/TM-2007-215024, AIAA-2007-5742, October 2007.

6. "Project Technical Requirements Specification for the Low Impact Docking System (LIDS) Government Furnished Equipment (GFE)," JSC-63686, Revision A, Release Date September 26, 2008.

7. "LIDS Seals Design Temperature" Memorandum from the LIDS Project, LIDS-09-002, January 28, 2009.

8. "Constellation Program Human-Systems Integration Requirements," Constellation Program document CxP 70024, Rev C, Release Date March 6, 2009.

9. "Standard Materials and Processes Requirements for Spacecraft," NASA-STD-(I)-6016, Release Date September 11, 2006, p. 31.

10. ASTM Standard E595, 2003e2, "Standard Test Method for Total Mass Loss and Collected Volatile Condensable Materials from Outgassing in a Vacuum Environment," ASTM International, West Conshohocken, PA, 2003.

11. "Constellation Program Structural Design and Verification Requirements," Constellation Program document CxP 70135, Baseline, Change 004, Release Date August 25, 2008.

12. de Groh III, H.C., Miller, S.K.R., Smith, I.M., Daniels, C.C., and Steinetz, B.M., "Adhesion of Silicone Elastomer Seals for NASA's Crew Exploration Vehicle," NASA/TM-2008-215433, AIAA-2008-4625, October 2008.

13. Wasowski, J.L., Penney, N., Garafolo, N.G., and Daniels, C.C., "Leak Rates of a Candidate Main Interface Seal at Selected Temperatures," Proceedings of the $45^{\text {th }}$ ALAA/ASME/SAE/ASEE Joint Propulsion Conference, AIAA-2009-5320, AIAA, Denver, CO, August 2009.

14. Jackson, Jr., C.N., Sherlock, C.N., and Moore, P.O., Nondestructive Testing Handbook: Volume 1 Leak Testing, $3^{\text {rd }}$ ed., American Society for Nondestructive Testing, 1998, Chap. 5.

15. Smith, I.M., Daniels, C.C., Dunlap, P.H., and Steinetz, B.M., "Performance of Subscale Docking Seals Under Simulated Temperature Conditions," NASA/TM-2008-215428, AIAA-2008-4713, October 2008. 


\begin{tabular}{|c|c|c|}
\hline \multicolumn{2}{|c|}{ REPORT DOCUMENTATION PAGE } & $\begin{array}{l}\text { Form Approved } \\
\text { OMB No. 0704-0188 }\end{array}$ \\
\hline \multicolumn{3}{|c|}{ 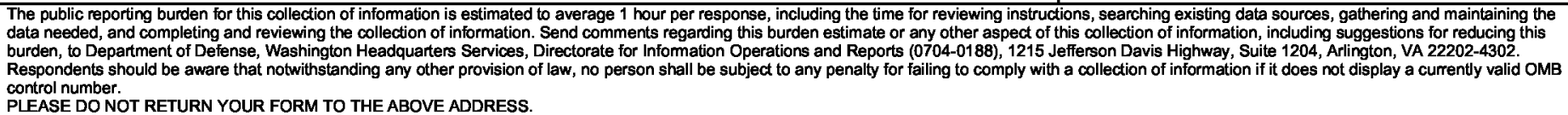 } \\
\hline $\begin{array}{l}\text { 1. REPORT DATE (DD-MM-YYYY) } \\
01-04-2010\end{array}$ & $\begin{array}{l}\text { 2. REPORT TYPE } \\
\text { Technical Memorandum }\end{array}$ & 3. DATES COVERED (From - To) \\
\hline \multirow{3}{*}{\multicolumn{2}{|c|}{$\begin{array}{l}\text { 4. TITLE AND SUBTITLE } \\
\text { Pressure Decay Testing Methodology for Quantifying Leak Rates of Full-Scale Docking } \\
\text { System Seals }\end{array}$}} & 5a. CONTRACT NUMBER \\
\hline & & 5b. GRANT NUMBER \\
\hline & & 5c. PROGRAM ELEMENT NUMBER \\
\hline \multirow{3}{*}{\multicolumn{2}{|c|}{$\begin{array}{l}\text { 6. AUTHOR(S) } \\
\text { Dunlap, Patrick, H., Jr.; Daniels, Christopher, C.; Wasowski, Janice, L.; Garafolo, Nicholas, } \\
\text { G.; Penney, Nicholas; Steinetz, Bruce, M. }\end{array}$}} & 5d. PROJECT NUMBER \\
\hline & & 5e. TASK NUMBER \\
\hline & & $\begin{array}{l}\text { 5f. WORK UNIT NUMBER } \\
\text { WBS } 644423.06 .31 .04 .01 .03 .22\end{array}$ \\
\hline \multicolumn{2}{|c|}{$\begin{array}{l}\text { 7. PERFORMING ORGANIZATION NAME(S) AND ADDRESS(ES) } \\
\text { National Aeronautics and Space Administration } \\
\text { John H. Glenn Research Center at Lewis Field } \\
\text { Cleveland, Ohio } 44135-3191\end{array}$} & $\begin{array}{l}\text { 8. PERFORMING ORGANIZATION } \\
\text { REPORT NUMBER } \\
\text { E-17231 }\end{array}$ \\
\hline \multirow{2}{*}{\multicolumn{2}{|c|}{$\begin{array}{l}\text { 9. SPONSORING/MONITORING AGENCY NAME(S) AND ADDRESS(ES) } \\
\text { National Aeronautics and Space Administration } \\
\text { Washington, DC 20546-0001 }\end{array}$}} & $\begin{array}{l}\text { 10. SPONSORING/MONITOR'S } \\
\text { ACRONYM(S) } \\
\text { NASA }\end{array}$ \\
\hline & & $\begin{array}{l}\text { 11. SPONSORING/MONITORING } \\
\text { REPORT NUMBER } \\
\text { NASA/TM-2010-216244 }\end{array}$ \\
\hline \multicolumn{3}{|c|}{$\begin{array}{l}\text { 12. DISTRIBUTION/AVAILABILITY STATEMENT } \\
\text { Unclassified-Unlimited } \\
\text { Subject Category: } 37 \\
\text { Available electronically at http://gltrs.grc.nasa.gov } \\
\text { This publication is available from the NASA Center for AeroSpace Information, 443-757-5802 }\end{array}$} \\
\hline
\end{tabular}

\section{SUPPLEMENTARY NOTES}

\section{ABSTRACT}

NASA is developing a new docking system to support future space exploration missions to low-Earth orbit and the Moon. This system, called the Low Impact Docking System, is a mechanism designed to connect the Orion Crew Exploration Vehicle to the International Space Station, the lunar lander (Altair), and other future Constellation Project vehicles. NASA Glenn Research Center is playing a key role in developing the main interface seal for this docking system. This seal will be relatively large with an outside diameter in the range of 54 to 58 in. $(137$ to $147 \mathrm{~cm})$. As part of this effort, a new test apparatus has been designed, fabricated, and installed to measure leak rates of candidate full-scale seals under simulated thermal, vacuum, and engagement conditions. Using this test apparatus, a pressure decay testing and data processing methodology has been developed to quantify full-scale seal leak rates. Tests performed on untreated 54 in. diameter seals at room temperature in a fully compressed state resulted in leak rates lower than the requirement of less than $0.0025 \mathrm{lbm}$, air per day (0.0011 $\mathrm{kg} /$ day). 15. SUBJECT TERMS

Seals; Leakage; Design; Test; Docking; Crew Exploration Vehicle

\begin{tabular}{|c|c|c|c|c|c|}
\hline \multicolumn{3}{|c|}{ 16. SECURITY CLASSIFICATION OF: } & \multirow{2}{*}{$\begin{array}{l}\text { 17. LIMITATION OF } \\
\text { ABSTRACT } \\
\text { UU }\end{array}$} & \multirow{2}{*}{$\begin{array}{l}\text { 18. NUMBER } \\
\text { OF } \\
\text { PAGES } \\
22\end{array}$} & \multirow{2}{*}{$\begin{array}{l}\text { 19a. NAME OF RESPONSIBLE PERSON } \\
\text { STI Help Desk (email:help@sti.nasa.gov) } \\
\text { 19b. TELEPHONE NUMBER (include area code) } \\
\text { 443-757-5802 }\end{array}$} \\
\hline $\begin{array}{l}\text { a. REPORT } \\
\text { U }\end{array}$ & $\begin{array}{l}\text { b. ABSTRACT } \\
\text { U }\end{array}$ & $\begin{array}{l}\text { c. THIS } \\
\text { PAGE } \\
\text { U } \\
\end{array}$ & & & \\
\hline
\end{tabular}



